ADOLESCENT SEXUAL HEALTH LETTERS

If you have a burning desire to respond to a paper published in Sex Transm Inf, why not make use of our "rapid response" option?

Log on to our website (www.sex transinf.com), find the paper that interests you, click on "full text" and send your response by email by clicking on "eletters submit a response".

Providing it isn't libellous or obscene, it will be posted within seven days. You can retrieve it by clicking on "read eletters" on our homepage.

The editors will decide, as before, whether to also publish it in a future paper issue.

\section{HIV tests in young adolescents attending a GUM clinic}

A pretest counselling session is recommended by the General Medical Council before carrying out an HIV test and it is generally accepted that adolescents deemed competent enough to understand the counselling process can have an HIV test without parental consent. A recent survey in the United Kingdom showed that $79 \%$ of clinics were prepared to test for HIV infection in children under the age of $16 .{ }^{1}$ We reviewed the characteristics of adolescents between the ages of 13 and 16 seen in the Coventry genitourinary medicine (GUM) clinic for an HIV test between 1990 and 2000 (table 1). This was part of a larger review of GUM attendances by children, the results of which have been published.

The commonest mode of presentation was a specific request for an HIV test. This was the case in $32(39.0 \%)$ adolescents. Eighteen adolescents $(22.0 \%)$ coming in requesting a check up were also offered an HIV test, $22(26.8 \%)$ alleged rape/assault, 14 (17.1\%) complained of a discharge, and four $(4.9 \%)$ had a needlestick injury.

Ten $(12.2 \%)$ of the adolescents seen had a sexually transmitted infection diagnosed (eight girls ( $11.4 \%$ ) versus two boys ( $16.7 \%$ ) $\mathrm{p}=0.6)$. Genital chlamydial infection was

Table 1 Demographics

\begin{tabular}{ll}
\hline Total number & 82 \\
Female & $70(85.4 \%)$ \\
Accepting to have HIV test & $70(85.4 \%)$ \\
Median age & 15 \\
Virgins & $8(9.8 \%)$ \\
Prostitutes & $3(3.7 \%)$ \\
Injecting drug users & $3(3.7 \%)$ \\
Positive for HIV antibodies & 0 \\
\hline
\end{tabular}

diagnosed in five cases, gonorrhoea in two cases, and there was one case each of genital herpes, Trichomonas vaginalis, and genital wart infection. Having a sexually transmitted infection diagnosed was associated with complaining of a discharge ( $12.5 \%$ versus $50.0 \%$ $\mathrm{p}=0.003$ ) and prostitution ( $1.4 \%$ versus $20.0 \%$ $\mathrm{p}=0.03$ ) but not with any other presenting complaint.

Adolescents coming in specifically requesting an HIV test were more likely to accept it following counselling than those who did not (96.9\% versus $78.0 \%, p=0.02)$. Acceptance of HIV test was, however, unrelated to the sex of child, prostitution, more than one partner in the previous year, or being diagnosed with a sexually transmitted infection. There was no statistically significant difference between those claiming rape/assault and those who were not in having an HIV test after counselling $(95.5 \%$ versus $81.7 \%, p=0.1)$.

There is no specific literature regarding the factors associated with HIV testing in young adolescents. A study of sexually active 16-19 year olds in Massachusetts found that infrequent condom use and a history of sexually transmitted disease were not significantly associated with voluntary HIV testing. ${ }^{3}$ Having had more than one sexual partner in the past year and discussing HIV/AIDS with a doctor were however associated with voluntary HIV testing. Previous discussion of HIV testing with a healthcare provider was also identified as a predictor of HIV testing in another study. ${ }^{4}$ Misconceptions about HIV test results and condom use as well as not having discussed HIV with a teacher are also associated with voluntary HIV testing.

It has been shown that most adolescents engaging in high or moderate HIV risk behaviour continued to do so into young adulthood. Knowledge about HIV infection and its prevention, estimates of personal risk or exposure to HIV test counselling were not associated with a change in behaviour. ${ }^{5}$ Effort must therefore be directed at research into adolescent risk behaviour change.

A Apoola, S P Allan, A A Wade Whittall Street Clinic, Birmingham B4 6DH, UK Correspondence to: A Apoola ade.apoola@bscht.wmids.nhs.uk

\section{References}

1 Williams $O$, Forster $G$, Robinson A Screening for sexually transmitted infections in children and adolescents in the United Kingdom: British Co-operative Clinical Group. Int J STD AIDS 2001:12:487-92.

2 Apoola A, Wade AA, Allan PS. Why do children attend the genitourinary medicine clinic? Int J STD AIDS 2001;12:759-60.

3 Samet JH, Winter MR, Grant L, et al. Factors associated with HIV testing among sexually active adolescents: a Massachusetts survey. Pediatrics 1997; 100(Pt 1):371-7.

4 Goodman E, Tipton AC, Hecht L, et al. Perseverance pays off: health care providers' impact on HIV testing decisions by adolescent females. Pediatrics 1994;94(Pt 1):878-82.

5 Stiffman AR, Earls F, Dore P, et al. Changes in acquired immunodeficiency syndrome-related risk behavior after adolescence: relationships to knowledge and experience concerning human immunodeficiency virus infection. Pediatrics 1992;89(P+ 1):950-6.

Accepted for publication 5 July 2002

\section{Sexual and reproductive health among female adolescents: preliminary results}

The recognition of adolescence as an essential formative stage of life has implications for programming content and approaches. ${ }^{1}$ Young people have to be treated as people in their own right, and their individual needs considered on a case to case basis. The realisation that this is a time of significant opportunities and risks highlights the urgency to deal directly with sensitive topics such as sex and drugs. ${ }^{2}$

The aim of this study was to identify demographic, behavioural and clinical factors for STI and unplanned pregnancy among female adolescents assisted by the family health programme (PSF) of Vitória Municipality in Brazil. A cross sectional study was performed among female adolescents (15-19 years old) assisted by the PSF. Participants were screened for Chlamydia trachomatis and Neisseria gonorrhoeae using ligase chain reaction (LCR) applied to urine and answered a face to face questionnaire. Standard descriptive statistical analysis was performed. Prevalence rates were calculated to reflect the relative frequency of each disease, with corresponding 95\% confidence intervals (CI). The national school of public health (FIOCRUZ) ethics committee approved this study. Written, informed consent was obtained by all participants and their parents.

The study included 149 adolescents. Mean age was 17.2 (SD 1.5) years; mean education was 8.3 (SD 2.9) years of schooling, and the mean age of the first sexual intercourse was 15.4 (SD 1.6) years. Seventy per cent of adolescents have already had sexual intercourse. Among those the prevalence rate of CT was $11.4 \%$ (95\% CI 7.6 to 14 ), $4.0 \%$ (95\% CI 2.1 to 5.2) of GC. Behaviour and clinical data are reported in table 1 . There was statistical significance between chlamydia infection and previous STI (OR $=20.1$, 95\% CI: 5.9 to 67.9); gonorrhoea and no condom use $(\mathrm{OR}=1.2,95 \% \mathrm{CI}$ : 1.06 to 1.12); and gonorrhoea and alcohol abuse $(\mathrm{OR}=1.3,95 \% \mathrm{CI}$ : 1.1 to 2.1$)$. Clinical problems identified were genital ulcer $6.0 \%$, dysuria $15.4 \%$, inguinal lymphadenopathy $12.1 \%$, vaginal bleeding $3.4 \%$, and pelvic pain $5.4 \%$.

STIs deserve attention not only because of their high prevalence but also because they frequently go undetected and untreated, and often result in serious sequelae and association with HIV infection. ${ }^{3}$ High prevalence rates associated with high frequency of risk were observed in this ongoing study. These two factors identify female adolescents as an important group to reach with STI including HIV prevention efforts.

These data are descriptive and need to be completed but they are in agreement with the last research about Brazilian sexuality. It was reported that adolescents have their first intercourse earlier than the older generation and the knowledge about STI/AIDS does not modify the exposition. ${ }^{4}$ Eighteen per cent of adolescents in Brazil become pregnant at least once and $54.1 \%$ among the married ones use some method of contraception. ${ }^{5}$ The preliminary results suggest that humane, healthcare based, STI/HIV prevention services in the health family programme can be an acceptable intervention, as well as one that is highly targeted epidemiologically. Screening, treatment and prevention counselling, and support in communities should be considered 
Table 1 Behavioural and clinical data among female adolescents

\begin{tabular}{lrr}
\hline Variables & No & $\%$ \\
\hline Tobacco use & 45 & 30.2 \\
Alcohol regular use & 39 & 26.2 \\
Cannabis use & 22 & 14.8 \\
Illicit drug abuse & 56 & 37.6 \\
Access to information about sexuality & 104 & 69.8 \\
Access to information about contraception & 86 & 57.7 \\
Regular medical consultation & 92 & 61.7 \\
Vaginal intercourse & 97 & 65.1 \\
Anal intercourse & 8 & 5.4 \\
Regular condom use* & 31 & 31.9 \\
Previous STI* & 10 & 10.3 \\
Pregnancy* & 26 & 26.8 \\
Rape* & 13 & 13.4 \\
\hline \multirow{2}{*}{ * Data related to 97 adolescents that reported sexual intercourse. } &
\end{tabular}

and evaluated as a core component of STI/HIV prevention efforts in many or most places where STIs are public health problems.

A E Miranda, A J Gadelha "Escola Nacional de Saúde Pública", FIOCRUZ, Rio de Janeiro, Brazil, Universidade Federal do Espírito Santo; Espírito Santo, Brazil

Correspondence to: Angelica Espinosa Miranda Rua Luiza Grinalda, 207 Vila Velha, ES, Brazil, ZC 29100-240; espinosa@escelsa.com.br

\section{References}

1 PanAmerican Health Organization. Plan of action for health and development of adolescents and youth in the Americas, 1998-2001. Washington, DC: PanAmerican Health Organization, 1998

2 World Health Organization. Programming for adolescent health and development: repor of a WHO/UNFPA/UNICEF Study Group on Programming for Adolescent Health. Geneva: WHO, 1999

3 Fleming DT, Wasserheit JN. From epidemiological synergy to public health policy and practice: the contribution of other sexually transmitted diseases to sexual transmission of HIV infection. Sex Transm Infect 1999;75:3-17

4 CEBRAP-centro brasileiro de análise e planejamento. Comportamento sexual da população brasileira e percepções sobre HIV e AIDS. Brasilia: Ministério da Saúde/SPS/PN DST/AIDS, July 1999.

5 BENFAM. Brasil-Pesquisa Nacional sobre demografia e saúde, 1996. Brasilia: BENFAM, 1997.

Accepted for publication 14 June 2002

\section{LETTERS}

\section{Factors affecting co-infection with genital chlamydia and genital gonorrhoea in an urban genitourinary medicine clinic}

Co-treatment for chlamydia is common practice when gonorrhoea is diagnosed in a UK genitourinary medicine setting. In Glasgow, the incidence of gonorrhoea across the city has tripled from 1995 to $2000 .{ }^{1}$ Given this rise, we investigated whether our practice of co-treatment was of continued benefit. We examined all patients presenting to the Glasgow Royal Infirmary Genitourinary Medicine (GUM) Service (including the Steve Retson Project service for gay men) between 1 April 1997 and 30 September 2000 who had genita gonorrhoea diagnosed on routine culture. We diagnosed genital chlamydia co-infection by ligase chain reaction (LCR) on first pass urine (for men) or endocervical swab (for women).

We diagnosed gonorrhoea in 351 attenders (287 men, 64 women), of whom 86 (25\%; 95\% CI $20 \%$ to $29 \%$ ) were co-infected. Co-infection was significantly more common in women than men $(29 / 64$ (48\%) $v 57 / 287(20 \%) ; \mathrm{p}=0.02$ ). Homosexual or bisexual men were significantly less likely to be co-infected than heterosexual men (15/134 (11.0\%) v 42/153 (28\%); p = $0.001)$. Co-infection became less common with increasing age (15-19 years 43\%; 20-24 years $34 \%$; $>24$ years $18 \%$; $\chi^{2}$ for trend $=15.4 ; \mathrm{p}$ $<0.0001$ ) (see table wl on STI website). Logistic regression modelling showed young age and female sex to be independent predictors of co-infection, while homo/bisexuality was protective (see table w2 on STI website).

We recommend continuing co-treatment for chlamydia in all women and heterosexual men presenting with gonorrhoea in our setting. However, in common with other recent findings ${ }^{2}$ co-infection with genital chlamydia is uncommon in male homosexual or bisexual attenders with genital gonorrhoea, and cotreatment may not be necessary in this group.

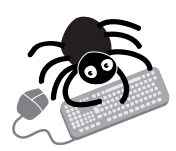

Two tables can be found on the STI website

Presented in part at the MSSVD Spring Meeting May 2001.

L Hijazi, C Thow, A J Winter Sandyford Initiative, Glasgow G3 7NB, UK

Correspondence to: A J Winter andy.winter@glacomen.scot.nhs.uk

References

1 Scoular A, Winter AV, Young $\mathrm{H}$, et al. Gonorrhoea in Glasgow 1994-2000. Health Weekly Report 2002;32:22-4.

2 Dragovic B, Greaces K, Vashisht V, et al. Chlamydial co-infection among patients with gonorrhoea. Int J STD AIDS 2002;13:261-3.

Accepted for publication 21 May 2002

\section{Screening for STIs in individuals with HIV infection}

In Australia, Victoria has seen an increase in new HIV cases from 1999 to $2000,{ }^{1}$ and this rise has been sustained in 2001. The rise primarily involves men who have sex with Scottish Centre for Infection and Environmental men (MSM), where rates of unprotected anal intercourse and bacterial sexually transmitted infections (STIs) have also increased. ${ }^{1}$ As bacterial STIs enhance HIV transmission, screening for asymptomatic infections may reduce the incidence of HIV.

A sexual health service in Melbourne reviewed medical records of MSM clients with HIV infection. This was conducted to determine how commonly STI screening of asymptomatic clients is performed and the proportion with bacterial STIs. At the sexual health clinic the records of MSM with HIV care primarily at that clinic between 10 January 2001 and 1 March 2002 were reviewed. Any record of bacterial STI screening in the last year, the anatomical sites screened, and the laboratory results of screening were collected on printed forms. At the Alfred hospital a pilot programme screening asymptomatic clients with HIV $(\mathrm{n}=40)$ was undertaken in the outpatient department between 30 October 2001 and 4 December 2001.

Of the 66 sexual health clinic records fulfilling the criteria, 22 (33\%) had screening for bacterial STIs, and eight were tested at all anatomical sites of infection (urethra, rectum, throat). Of the 22 tested, three (14\%) tested positive for Neisseria gonorrhoeae (NG) by culture and/or Chlamydia trachomatis (CT) by ligase chain reaction (LCR). Three had rectal infection ( $\mathrm{NG}=2, \mathrm{CT}=3$ ), two also had pharyngeal infection ( $\mathrm{NG}=2$ ), and one also had urethral infection $(\mathrm{CT}=1)$. At the Alfred Hospital 40 clients had swabs taken from all sites. Of these 40, eight (20\%) HIV infected clients had rectal NG detected by polymerase chain reaction (PCR) with confirmatory assay.

We identified a relatively high proportion of infections in those screened-11 positive of the 62 tested ( $18 \%, 95 \%$ CI $9 \%$ to 30\%). These findings to do not mean that these individuals have been placing others at risk of HIV transmission because STIs may be acquired from unprotected sexual contact with other HIV infected individuals, or through sexual contact that is low risk for HIV transmission. Nevertheless, it would seem prudent to reduce the prevalence of STIs by making screening a routine part of the management of MSM. In the United States STI screening is recommended, ${ }^{3}$ and screening of MSM is also recommended in the draft "STI management guidelines for priority populations" from the Australasian College of Sexual Health Physicians (Chris Bourne, personal communication).

\section{Contributors}

The data extraction was carried out by all authors and analysed by NL and CF. The article was drafted by all authors and all have approved the final draft. The authors declare that they have no conflict of interest in connection with this paper.

The completion of medical record reviews, the analysis, and drafting of this letter did not involve funding.

N A Lister, C K Fairley Department of Public Health, The University of Melbourne, Australia

T Read Carlton Clinic, 88 Rathdowne Street, Carlton 3053, Australia

A Mijch

HIV Services, Alfred Hospital, Department of Infectious Diseases, Alfred Hospital, Prahran, Vic 3181 , Australia 
Correspondence to: Professor C K Fairley, School of Population Health, 2nd Floor, 723 Swanston Street, Carlton 3053, Australia cfairley@unimelb.edu.au

\section{References}

1 Hocking J, Crofts N. HIV Surveillance in Victoria in 2000. Victorian Government Department of Human Services, Melbourne. Victorian Infectious Diseases Bulletin 2001;4:1-3.

2 Fleming DT, Wasserheit JN. From epidemiological synergy to public health policy and practice: the contribution of other sexually transmitted diseases to sexual transmission of HIV infection. Sex Transm Infect 1999;75:3-17.

3 Anonymous. HIV prevention through early detection and treatment of other sexually transmitted diseases-United States. Recommendations of the Advisory Committee for HIV and STD prevention. Mor Mortal Wkly Rep CDC Surveill Summ 1998;47(RR-12): 1-24.

Accepted for publication 13 June 2002

\section{Four layer discontinuous gradient for HIV}

Artificial insemination using processed semen is a risk reduction option, if they want children, for serodiscordant couples in whom the man is HIV positive. The main aim of this study was to develop a single semen processing technique to reduce HIV transmission risks to HIV negative wives without infection and to obtain better quality sperm.

\section{Methods}

After ethics committee approval and written informed consent, normozoospermic semen was provided by two asymptomatic HIV carriers. Discontinuous four layer density gradient whose fractions (Fr) were 1.065 (Fr 4), 1.085 (Fr 3), 1.110 (Fr 2), and 1.135 (Fr 1), was prepared with Puresperm. Semen washed with Hank's solution was laid on this gradient and centrifuged at $400 \mathrm{~g}$ for 30 minutes. The specimen of each fraction was extracted to determine sperm quality and to detect HIV RNA and proviral DNA using RT-PCR and PCR, respectively. Lymphocytes of an HIV non-carrier were co-cultured for 4 weeks with each fraction. HIV p24 antigen and proviral DNA after cocultivation with each fraction were determined by indirect immunofluorescence assay and polymerase chain reaction (PCR), respectively.

\section{Results}

The percentage collection of sperm from Fr 1 , Fr 2, Fr 3, and Fr 4 was 3\% (SD 2\%), 32\% (9\%), $19 \%(8 \%)$, and $10 \%(4 \%)$, respectively. Motility rate was 55\% (19\%), 94\% (4\%), 57\% (25\%), and $19 \%(11 \%)$, respectively. HIV proviral DNA and HIV RNA were detected only from Fr 4. HIV p24 antigen was observed in the lymphocytes co-cultivated with Fr 4 and from the positive control, but was not observed in other fractions. HIV proviral DNA was not detected from Fr 2 or Fr 3 (tables 1 and 2).
Table 2 Detection of HIV p24 antigen and proviral DNA after 4 weeks' co-cultivation with each fraction and carrier's PBL

\begin{tabular}{lll}
\hline & HIV p24 antigen & HIV DNA \\
\hline Fr 1 & neg & pos \\
Fr 2 & neg & neg \\
Fr 3 & neg & neg \\
Fr 4 & pos & pos \\
Carrier's PBL & pos & pos \\
\hline
\end{tabular}

$\mathrm{PBL}=$ peripheral blood lymphocytes

\section{Discussion}

HIV discordant couples have a risk of transmission generally if they wish to have a baby. ${ }^{1}{ }^{2}$ Semprini et al ${ }^{3}$ reported continuous gradient centrifugation followed by a swim up procedure, and Marina et $a l^{4}$ carried out a similar method but HIV was detected in 5.6\% of 107 samples. However, the condition of the sperm, after these processes, was not always sufficient for intrauterine insemination.

We have developed a novel semen single processing technique to reduce HIV RNA and HIV proviral DNA to undetectable levels in the fraction whose sperm quality was higher than others. Furthermore, this fraction was confirmed to have no HIV infectivity in vitro. This method appears to be an attractive alternative for HIV discordant couples.

\section{Contributors}

KK and YA contributed to laboratory work; AY referred HIV positive volunteers.

K Kakimoto, Y Ando, A Yoshioka International Medical Centre of Japan, Tokyo, Japan Correspondence to: K Kakimoto kakimoto@sannet.ne.jp

\section{References}

Saracco A, Musicco M, Nicolosi A, et al. Man-to-woman sexual transmission of HIV longitudinal study of 343 steady partner of infected men. J AIDS 1993;6:497-502.

2 Lazzarin A, Saracco A, Musicco M, et al. Man-to-woman sexual transmission of the human immunodeficiency virus. Risk factors related to sexual behavior, man's infectiousness, and woman's susceptibility. Arch Intern Med 1991:151:2411-6.

3 Semprini AE, Levi-Setti $P$, Bozzo $M$, et al. Insemination of HIV-negative women with processed semen of HIV-positive partners. Lancet 1992;340:1317-9.

4 Marina S, Marina F, Alcolea R, et al. Human immunodeficiency virus type 1 - serodiscordant couples can bear healthy children after undergoing intrauterine insemination. Fertil Steril 1998;70:35-9.

Accepted for publication 1 May 2002

Table 1 Sperm characteristics and detection of HIV in each fraction

\begin{tabular}{|c|c|c|c|c|c|c|}
\hline & $\begin{array}{l}\text { Sperm } \\
\text { collection } \\
\text { rate }(\%)\end{array}$ & $\begin{array}{l}\text { Sperm } \\
\text { motility rate } \\
(\%)\end{array}$ & HIV RNA & HIV DNA & $\begin{array}{l}\text { HIV p24 antigen } \\
\text { after co-cultivation }\end{array}$ & $\begin{array}{l}\text { HIV DNA } \\
\text { after } \\
\text { co-cultivation }\end{array}$ \\
\hline Fr 1 & $3(2)$ & 55 (19) & negative & negative & negative & positive \\
\hline Fr 2 & 32 (9) & $94(4)$ & negative & negative & negative & negative \\
\hline Fr 3 & $19(8)$ & 57 (25) & negative & negative & negative & negative \\
\hline Fr 4 & $10(4)$ & 19 (11) & positive & positive & positive & positive \\
\hline
\end{tabular}

\section{Erythema nodosum induced by chancroid}

Erythema nodosum is a type of panniculitis which is often regarded as a complex reaction pattern to various aetiological factors of infective and non-infective origin. ${ }^{1}$ Infective agents outnumber inflammatory causes and drugs in causation of erythema nodosum in the developing countries. Almost all the infective agents including aerobic and anaerobic bacteria, viruses, fungi, parasites and mycobacteria can induce eruption of erythema nodosum. ${ }^{2}$ Among sexually transmitted infections lymphogranuloma venereum has been known to be associated with erythema nodosum not infrequently.

A 23 year old woman presented with genital ulcer disease and painful rash over the legs of l week's duration. There was no history of trauma, fever, or drug intake. She had a single stable sexual partner who was apparently unaffected. Examination revealed a single, $1-1.5 \mathrm{~cm}$ size, irregular tender ulcer on the right labia minora with undermined margins and bleeding on touch. The right inguinal lymph nodes were firm, moderately enlarged, and tender. Speculum and vaginal examination was normal. Examination of the perianal region, perineum, and other mucosae was also normal.

Multiple tender, erythematous nodular subcutaneous lesions with dusky erythema were present over both shins, calves, and ankle joints. Investigations revealed a normal complete blood count, serum biochemistry, urinalysis and blood sugar. VDRL, HIV-l ELISA, and HBsAg were negative. Dark ground illumination, smears, and cultures from the ulcer did not reveal aetiological diagnosis. Histopathology from the ulcer revealed an ulcerated surface with necrosis and neutrophilic infiltrate deeper to which a zone of new blood vessel formation with marked endothelial proliferation and a lymphoplasmacytic infiltrate was observed. These features were consistent with diagnosis of chancroid while histopathology of leg lesions confirmed it to be septal panniculitis consistent with a diagnosis of erythema nodosum. The patient was treated with erythromycin stearate 500 mg 6 hourly for 7 days. The genital ulcer healed completely in 7-10 days but the lesions of erythema nodosum subsided completely in 5-7 days without any other treatment.

Erythema nodosum as a cutaneous reaction pattern was first observed by Willan in $1798 .{ }^{4} \mathrm{~A}$ female preponderance with a ratio of 3:1 is often observed in adults compared to an equal incidence at prepubertal age. Although the exact pathogenesis of erythema nodosum is not known, it has been regarded as a immune complex, deposition disease which prefers the richly supplied vascular adipose tissue of the legs.

In the present patient erythema nodosum and chancroid had a strong temporal correlation as erythema nodosum immediately followed the appearance of the chancroid and resolved completely with its resolution. Although erythema nodosum is known to be associated with innumerable infective agents, to the best of our knowledge chancroid leading to causation of erythema nodosum has not been observed before.

C Kaur, G P Thami

Department of Dermatology and Venereology, Government Medical College Hospital, Sector 32 B, Chandigarh 160030, India drgurvinder@mantraonline.com 


\section{References \\ 1 Ryan TJ. Cutaneous vasculitis. In: Champion $\mathrm{RH}$, Burton JL, Burns D A, et al, eds. Rook/Wilkinson/Ebling. Textbook of dermatology. Vol 3, 6th ed. Oxford: Blackwell Science, 1998:2155-225. \\ 2 Bondi EE, Margolis DJ, Lazarus GS. Panniculitis. In: Freedberg IM, Eisen AZ, Wolff $\mathrm{K}$, et al, eds. Dermatology in general medicine. Vol 1, 5th ed. New York: McGraw-Hill, 1999:1275-89. \\ 3 Kousa M, Saikko P, Kanerva L. Erythema nodosum in chlamydial infections. Acta Dermatol Venereol 1980;60:319-22. \\ 4 Willan R, ed. On cutaneous diseases. London: Johnson, 1798.}

Accepted for publication 5 June 2002

\section{Gonococcal perianal abscess: re-emergence after cessation of co-trimoxazole}

We report a case of perianal abscess due to Neisseria gonorrhoeae, which appears to have been suppressed but not eradicated by chronic low dose co-trimoxazole for a period of almos 6 months between acquisition and diagnosis.

The patient was a 34 year old HIV infected homosexual man treated with didanosine, stavudine, and nevirapine with a HIV viral load of 500 copies per $\mathrm{ml}$ and a CD4 lymphocyte count of $280 \times 10^{6} / \mathrm{l}$. He was taking co-trimoxazole $400 \mathrm{mg} / 80 \mathrm{mg}$ once daily to prevent Pneumocystis carinii pneumonia (PCP).

He reported last having receptive anal sex in June 2000. This was unprotected, with a casual partner at a "gay" sauna. Three weeks later he reported a perianal abscess which discharged spontaneously, requiring dressings for a few days. A sinus was observed and he was booked for elective surgery. He remained well for 5 months

Co-trimoxazole PCP prophylaxis was stopped in November 2000 as his CD4 T lymphocyte count had remained above 200. Two weeks later (and almost 6 months after the last reported anal sex) he presented with purulent discharge emerging from a sinus approximately $3 \mathrm{~cm}$ from the anus.

$N$ gonorrhoeae (sensitive to penicillin, ceftriaxone, and ciprofloxacin) and Bacteroides species were cultured from this discharge. Swabs from the rectum, throat, and urethra as well as urine were negative for $N$ gonorrhoeae and Chlamydia trachomatis by polymerase chain reaction (PCR).

Oral ciprofloxacin was started but pain, swelling, and perianal cellulitis led to his admission to hospital where he was treated with intravenous ceftriaxone and metronidazole and surgical drainage.

Gonococcal perianal abscesses were reported in the pre-antibiotic era ${ }^{1}$ but have disappeared from contemporary descriptions of gonorrhoea, whereas Bartholin's, periurethral, and tubo-ovarian gonococcal abscesses are described.

The isolation of Bacteroides species and the worsening of the infection despite ciprofloxacin suggest that anaerobic organisms probably played a part in the development of an abscess, consistent with animal inoculation experiments. ${ }^{3}$ Another possible factor was the moderate immunosuppression (CD4 count of 280) from his HIV infection.

Six months passed from the time of infection to diagnosis, during which the patient was largely free of symptoms which then developed when co-trimoxazole was stopped. The likely explanation is that the co-trimoxazole was suppressing the gonococcal infection without curing it. The failure to detect $N$ gonorrhoeae by PCR from the rectal specimen raises the possibility that $\mathrm{CO}$ trimoxazole may have eradicated a rectal infection in this case while only suppressing an extragenital manifestation.

It is now standard practice to stop PCP prophylaxis when CD4 counts rise above $200 \times$ $10^{6} / 1$ in patients taking antiretroviral therapy. This may in turn have some impact on both the transmission and the manifestations of gonorrhoea in these patients, perhaps even contributing to increases in gonorrhoea in HIV infected populations. ${ }^{5}$

T Read

Melbourne Sexual Health Centre, 580 Swanston Street, Carlton, Victoria 3053, Australia

A Mijch

Alfred Hospital, Prahran, Victoria 3181, Australia

L Ostergaard

Research Unit Q, Department of Infectious Diseases, Aarhus University Hospital, Skejby Sygehus, DK-8200 Aarhus N, Denmark

Correspondence to: T Read; tread@mshc.org.au

\section{References}

1 Hayes H. Gonorrhoea of the anus and rectum-report of 75 cases. JAMA 1929;93:1878-81

2 Hook EW, Handsfield HH. Gonococcal infections in the adult. In: Holmes KK, et al. Sexually transmitted diseases. 3rd ed. New York: McGraw Hill, 1999:451-66.

3 Brook I. Induction of subcutaneous and intraperitoneal abscesses in mice by Neisseria gonorrhoeae and Bacteroides species. Am J Obstet Gynecol 1986:155:424-9.

4 Lopez Bernaldo de Quiros JC, Miro JM, Pena JM, et al. A randomised trial of the discontinuation of primary and secondary prophylaxis against Pnemocystis carinii pneumonia after highly active antiretrovira therapy in patients with HIV infection. N Engl J Med 2001;344: 159-67.

5 Scheer S, Lee Chu P, Klausner JD, et al. Effect of highly active antiretroviral therapy on diagnoses of sexually transmitted diseases in people with AIDS. Lancet 2001;357:432-40.

Accepted for publication 14 June 2002

\section{Uptake of HIV testing in patients with a confirmed sexually transmitted infection}

UK seroprevalence rates indicate that up to $50 \%$ of HIV positive patients in genitourinary medicine (GUM) clinics remain undiagnosed. ${ }^{1}$ HIV is mainly identified in high risk patient groups. Sexually transmitted infections other than HIV (STIs) have been shown to facilitate and be associated with enhanced HIV transmission. ${ }^{2}$ Risk assessment for HIV, therefore, should target patients with an STI or history of recurrent STIs as a high risk group.

Targeting these patients to test for HIV at the time or 3 months after their STI diagnosis, is important as it will lengthen the "diagnosis interval" of patients testing HIV positive thereby conferring a better outcome, with respect to $\mathrm{HAART}^{3}$; identify patients with recent concurrent acquisition of HIV and a STI, entering a highly infective seroconversion phase; identify individuals with undiagnosed, established HIV infection and a newly acquired STI which promotes higher infectivity due to increased HIV viral shedding into genital secretions. ${ }^{45}$

Our study analysed the uptake of HIV testing among attendees who had a genitourinary screen at St Thomas's Hospital genitourinary medicine department between 1 and 31 December 1999.

It compared the uptake of HIV testing, either at the index visit in December or deferred to within the ensuing 3 months, between patients diagnosed with an STI (gonorrhoea, chlamydia, herpes simplex virus, and trichomoniasis (study group)) and patients receiving a negative STI screen (control group).

Of 318 attendees, 242 and 76 patients comprised the study and control groups respectively. Only $18 \%$ (59/318) of patients tested for HIV on the initial visit. Significantly fewer of the study group tested for HIV (14\%) compared to the control group (33\%) $(\mathrm{p}<0.01)$.

Of those who did not test for HIV, 11 and one patients deferred testing in the study and control groups respectively (table 1) However, none of the deferrers or initial non-testers re-attended for HIV testing in the following 3 months.

In view of this unacceptably low rate of HIV testing, both overall and in those patients with a confirmed STI, the following nterventions are now being introduced, aiming to improve these figures and comply with the sexual health strategy 2001 targets. ${ }^{6}$

- An "opt out" policy of HIV testing

- Additional waiting room posters and a new patient information leaflet about HIV is given to all patients at registration to read while they wait to be seen explaining the natural history, treatments available, benefits of early diagnosis, and mechanisms of reducing transmission. This enhances patient education and may expedite consultation length and waiting times for patients with restricted "time off" and/or other more pertinent issues to discuss

- Pretest counselling is reserved for high risk groups instead of being required routinely

- Patients are able to obtain their HIV results indirectly, without the inconvenience of a previously required second visit

- Educating all GUM staff to encourage a high offer rate of HIV testing to all patients, especially targeting high risk patients, which incorporates those with a confirmed STI.

\begin{tabular}{llll} 
Table 1 & \multicolumn{2}{l}{ Timeliness of HIV testing } & \\
\hline & $\begin{array}{l}\text { Tested for HIV at time } \\
\text { of attendance }\end{array}$ & $\begin{array}{l}\text { Deferred at time } \\
\text { of attendance }\end{array}$ & $\begin{array}{l}\text { Attended within } 3 \text { months } \\
\text { and tested for HIV }\end{array}$ \\
\hline $\begin{array}{l}\text { Study } \\
\text { Control }\end{array}$ & $34 / 242(14 \%)$ & $11 / 242(5 \%)$ & $2 / 46(4 \%)$ \\
$1 / 76(1 \%)$ & $2 / 11(18 \%)$ \\
\hline
\end{tabular}




\section{Contributors}

SD, CAR, and DL designed the study; SD and DL gathered and statistically analysed the data; SD, DL and CAR contributed to writing the paper.

Conflicting interests: There were no conflicting interests and no costs incurred.

S Day, D Lakhani, C Rodgers

Department of Genitourinary Medicine, Guy's and St Thomas's Hospital, London, UK

Correspondence to: Sara Day, Lydia Department Department of Genitourinary Medicine, St Thomas's Hospital, London SE 1 7EH, UK Sarah.Day@gstt.sthames.nhs.uk

\section{References}

1 Prevalence of HIV in the United Kingdom. Report of the unlinked anonymous prevalence monitoring programme United Kingdom: data to the end 1998. London: PHLS, 1999.

2 Grosskurth.H, Mosha F, Todd.J, et al. Impac of improved treatment of sexually transmitted diseases on HIV infection in rural Tanzania: randomised controlled trial. Lancet 1995:346:530-6.

3 PHLS. AIDS and HIV infection in the UK: monthly report. Communicable Disease Report 2000; 10: No13.

4 Moss GB, Overbaugh J, Welch $M$, et al. Human immunodeficiency virus DNA in urethral secretions in men associated with gonococcal urethritis and CD4 depletion. J Infect. Dis 1995; 172:1469-74.

5 Ghys PD, Fransen K, Diallo MO, et al. The association between cervicovaginal HIV shedding, sexually transmitted disease and immunosuppression in female sex workers in Abidjon, Cote d'Ivoire. AIDS 1997; 11:F85-93

6 The national strategy for sexual health and HIV: London: Department of Health, 2001.

\section{BOOK REVIEW}

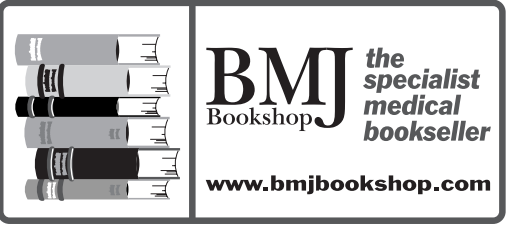

The Changing Face of HIV and AIDS. Scientific editors: Robin A Weiss, Michael W Adler, Sarah L Rowland-Jones. British Medical Bulletin 2001, Vol 58. Pp 223; 40. Published for the British Council by Oxford University Press. ISBN 0199224862.

Not many books nowadays try to summarise the broad field of HIV and AIDS. This British Medical Bulletin does attempt to do that, in line with its usual approach to providing substantial coverage of health subjects, but with suitable depth as well as breadth. The last (and first) British Medical Bulletin on this subject was published in 1988. It covered quite similar topics, but the main change is the depth of knowledge.
Although the title of this volume reflects the general sense that the face of the pandemic has indeed changed in many ways-not least the global spread, and the impact of antiretroviral therapies where they are available-the overwhelming impression had was how similar are the issues and perspectives it covers. This is partly a reflection of the extraordinary hothouse atmosphere of the early pioneering years, when we climbed the steep part of the learning curve with unparalleled speed. The subsequen years have been ones of consolidation, during which the detail has been explored and the basic ideas refined. This book reflects that, where the change in the face is in part the shift from an impressionistic image to a more fully representational portrait, evidently from the same original.

The chapters provide a balanced and compact, yet thorough, assessment of the main issues. The authors are active in the field; they have an appropriately British background for this series, yet their perspective is unequivocally global. The accounts are worthy, reliable, and authoritative. If this conveys the impression that they are rather dull to read, that was indeed my feeling. There was generally and disappointingly little sparkle or originality in the concepts or the writing. Where there was, it derived from a narrow focus on a small part of the canvas rather than any broader insight.

Who will use this volume? I would recommend it as a reliable and thorough review for a new entrant to the field. Those who work adjacent to it and who would like a compact, up to date summary would also be well served. Some of the chapters are an excellent springboard for detailed exploration of their topic. But those who already work on HIV/AIDS will find little to engage or excite them. They would probably feel, as I did, that the fascinating wider changes in the actual face of HIV/AIDS, which are palpable in their work, have scarcely been touched upon

Anthony J Pinching Department of Immunology, Barts and The London Queen Mary's School of Medicine and Dentistry, S Bartholomew's Hospital, West Smithfield, London EClA 7BE, UK

\section{NOTICES}

\section{International Herpes Alliance and International Herpes Management Forum}

The International Herpes Alliance has introduced a website (www.herpesalliance.org) from which can be downloaded patient information leaflets. Its sister organisation the International Herpes Management Forum (website: www.IHMF.org) has launched new guidelines on the management of herpesvirus infections in pregnancy at the 9th International Congress on Infectious Disease (ICID) in Buenos Aires.
Pan-American Health Organization, regional office of the World Health Organization

A catalogue of publications is available online (www.paho.org). The monthly journal of PAHO, the Pan American Journal of Public Health, is also available (subscriptions: pubsvc@tsp.sheridan.com).

\section{6th National Conference of the} Indian Association for the Study of Sexually Transmitted Diseases \& AIDS

18-20 October 2002, All India Institute of Medical Sciences, New Delhi, India

The last date for submission of abstracts for free papers is 1 September 2002. The registration fees for foreign delegates is $\$ 50$ (SAARC countries) and \$100 (other countries).

Further details: Indian Association for the Study of Sexually Transmitted Diseases \& AIDS (fax: (0)91 011686 2663; email: iasstd2002@sify.com).

\section{European Society for Gynaecological Endoscopy Expert Meeting on Pelvic Floor Disorders}

28-30 November 2002, Centro Médico Teknon, Barcelona, Spain

Further details: ESGE central office, OrgaMed, Essenestraat 77, B-1740 Ternat, Belgium (tel: +32 2582 0852; fax: +32 2582 1515; email: orgamed@village.uunet.be; web site: www.ESGE.org).

\section{Royal Society of Medicine Conference on Men's Sexual Health}

13 December 2002, The Royal Society of Medicine, 1 Wimpole Street, London, WIG OAE, UK

Is Viagra really the answer to impotence, or are men and their doctors relying on prescription pills and avoiding tackling the psychological causes behind the problem? Besides impotence and other sexual dysfunction, this meeting also looks a range of male sexual problems from STDs to prostate cancer, the effect of sex on the heart to the male menopause. Registration costs: Fellow: $£ 105$; Non-Fellow: £175; Student: £20. CPD: 5 credits; PGEA Applied For.

Further details: Ms Georgina Brodie, RSM Administration (tel: +44 (0) 207290 3856; fax: +44 (0) 207290 2977; email: georgina.brodie@rsm.ac.uk).

\section{International Congress of the Society of The Fetus as a Patient}

1-4 May 2003, Gran Hotel Sitges,

Barcelona-Sitges, Spain

Further details: (fax: +34 93418 7832; email: bcn2003@iudexeus.uab.es). 